\title{
ANTIOXIDANT METABOLISM IN WATER STRESSED PEANUT TREATED WITH DINICONAZOLE
}

\author{
G.C. RIVERO \\ Institute of Biology, University of the Philippines, Diliman, Philippines \\ and \\ D.M. ORCUTT \\ Department of Plant Physiology, Virginia Polytechnique Institute and State University, \\ Blacksburg, VA 24061-0331, USA
}

\begin{abstract}
The response of alpha-tocopherol, glutathione and ascorbate was studied in peanut (Arachis hypogea L, cv. NC-17) subjected to water stress and treated with a triazole fungicide, diniconazole (DINI). There was no significant difference in alpha-tocopherol levels between control and DINI treated plants. However, a 14\% increase was observed in alpha-tocopherol level in DINI treated, water stressed plants compared to water stressed plants. Total glutathione in DINI treated stressed plants increased by 13 and 31\% over control and water stressed plants, respectively. Ascorbate levels decreased significantly in all treatments compared to the control. These results indicate that DINI alleviates the oxidative damage caused by water stress by increasing total glutathione levels. However, DINI does not seem to affect alpha-tocopherol and ascorbate levels in peanuts under water stress.
\end{abstract}

\section{INTRODUCTION}

Protection against harmful oxidation of biomembranes is provided by several antioxidative systems, including a large array of enzymes and a variety of small molecules such as glutathione, beta-carotene, and the vitamins $\mathrm{C}$ and $\mathrm{E}$ (Finckh and Kunert 1985). In plants, vitamin $\mathrm{E}$ (alpha-tocopherol) is located mainly in the chloroplast (Bucke 1976) and a high concentration of the lipid-soluble vitamin is found in the chloroplast envelope (Lichtenthaler et al. 1981). Vitamin C (ascorbate), a reducing agent, is present in substantial amount in higher plants (Jones and Hughes 1983), and the water-soluble vitamin is generally regarded as a normal cellular constituent (Finckh and Kunert 1985).

The tripeptide glutathione is widely distributed in plant cells (Rennenberg 1982). It is implicated in the adaption of plants to environmental stress such as drought and extremes of temperature (Alscher 1989).

Glutathione, ascorbate and alpha-tocopherol are of special interest because of their demonstrated association with stress resistance. The present study evaluated the response of alpha-tocopherol, glutathione and ascorbate in water stressed peanut plants treated with diniconazole. 


\section{MATERIALS AND METHODS}

Peanut (Arachis hypogea L., cv. NC-17) seedlings were grown in controlled conditions, i.e. continuous illumination (392 uEm-2sec-1) and controlled temperature (28 \pm $2^{\circ} \mathrm{C}$ ). Treatments consisted of control, water stressed, DINI treated and DINI treated stressed plants arranged in a completely randomized block design with 10 replications. DINI was applied foliary at a rate of $4 \mathrm{mg} /$ plant (recommended field rate) every 2 weeks for 7 weeks commencing when the plants were 6 weeks old. Drought stress treatment began 4 days following initial DINI treatment and consisted of applying $125 \mathrm{ml}$ of distilled water to plants subjected to drought every 3 days versus $250 \mathrm{ml}$ to non-stressed plants. Harvested plants (117 days old) were frozen in liquid nitrogen, freeze dried and stored at $-23^{\circ} \mathrm{C}$ until analyzed for alpha-tocopherol, glutathione and ascorbate.

Alpha-tocopherol was extracted in $80 \%$ ethanol partitioned with hexane and the hexane layer analyzed using a Hewlett Packard Model 1090 HPLC, equipped with a fluorescence detector (294 nm excitation, $325 \mathrm{~nm}$ emission) following modified procedures of Cort et al. (1983) and Grumbach (1983). The hexane ran through a silica column (Hypersil 5 um, 200 x 4.6 mm, Hewlett Packard).

Glutathione and ascorbate extraction was accomplished by homogenizing leaf tissue in $2 \%$ metaphosphoric acid. The homegenate was centrifuged at $17000 \mathrm{~g}$ and the supernatant analyzed for glutathione (Griffith 1980) and ascorbate (Foyer and Halliwell 1977) using a Beckman DU-65 spectrophotometer at wavelengths $412 \mathrm{~nm}$ and $523 \mathrm{~nm}$, respectively.

\section{RESULTS AND DISCUSSION}

The following table reflects the responses of alpha-tocopherol, glutathione and ascorbate in water stressed peanut plants treated with DINI.

\begin{tabular}{|c|c|c|c|}
\hline \multicolumn{4}{|c|}{$\begin{array}{l}\text { Alpha-tocopherol, total glutathione and asc } \\
\text { NC-17) plants treated with diniconazole }\end{array}$} \\
\hline \multirow[t]{2}{*}{ TRT } & VITAMINE & GLUTATHIONE & VITAMIN C \\
\hline & $(\% \mathrm{DW})$ & (nMoles/gDW) & (uMoles/gDW) \\
\hline $\mathrm{C}$ & $0.57 \mathrm{~A}$ & 835.01B & $7.28 \mathrm{~A}$ \\
\hline $\mathrm{T}$ & $0.43 \mathrm{~B}$ & $880.40 \mathrm{AB}$ & 3.91B \\
\hline $\mathrm{CS}$ & $0.49 \mathrm{AB}$ & $719.86 \mathrm{C}$ & $4.65 \mathrm{~B}$ \\
\hline $\mathrm{TS}$ & $0.50 \mathrm{AB}$ & $946.14 \mathrm{~A}$ & $4.74 \mathrm{~B}$ \\
\hline
\end{tabular}

$\mathrm{C}=$ control; $\mathrm{T}=$ treated $\mathrm{w} / \mathrm{DINI} ; \mathrm{CS}=$ water stressed; $\mathrm{TS}=$ treated $\mathrm{w} / \mathrm{DINI}$ and water stressed. Value with different letters are significantly different at $\alpha=0.05$ (LSD). 
There was no significant difference in alpha-tocopherol levels between control and DINI treated plants. However, a 14\% increase was observed in alpha-tocopherol level in DINI treated stressed plants compared to water stressed plants. Earlier reports (Senaratna et al. 1985, Mackay et al. 1987) on antioxidant levels in stressed plants indicated an increase on the levels of total antioxidants. Mackay et al. (1987) evaluated the antioxidant potential of microsomal membranes and reported an increase in antioxidant potential of triazole (S-3307) treated wheat plants exposed to ozone. However, their analysis was made on total antioxidant potential of the lipid fraction, as the ability of the lipid extract to inhibit the in vitro oxidation of exogenous linoleic acid. The oxidation reaction was similar to that seen for alpha-tocopherol and thus, the antioxidant capacity of their samples were expressed as alpha-tocopherol equivalents (Mackay et al. 1987). In our study, alpha-tocopherol was measured directly by HPLC.

Ascorbate levels decreased significantly in all treatments compared to the control. There is evidence that ascorbate represents a reservoir of antioxidant potential to regenerate directly, under conditions of stress, the lipid-soluble primary antioxidant alpha-tocopherol (Packer et al. 1979; Leung et al. 1981). This could explain the significant decrease in ascorbate levels in water stressed and DINI treated water stressed plants compared to the control.

Total glutathione in DINI treated stressed plants increased by 13 and $31 \%$ over control and water stressed plants, respectively. In pea, a chilling-resistant species, total glutathione decreased only slightly, but was still higher than that in cucumber, a chilling-sensitive species (Wise and Naylor 1987). The results presented here indicate that DINI alleviates the oxidative damage caused by water stress by increasing the total glutathione levels.

\section{SUMMARY}

Total glutathione levels increased in stressed peanut plants treated with diniconazole and could be a factor in drought resistance.

Diniconazole does not seem to affect alpha-tocopherol and ascorbate levels in peanuts under water stress. 


\section{ACKNOWLEDGEMENT}

This study was part of a research conducted during the senior author's US-AID post-doctoral fellowship at the Department of Plant Pathology, Physiology and Weed Science, Virginia Polytechnique Institute and State University, Blackburg, VA 24061, USA from October, 1989 to August, 1990. Special thanks are due to Dr. R. Madamachi and Ms. N.R. Hopkins from the same department for their invaluable assistance.

\section{REFERENCES}

ALSCHER, R.G. 1989. Physiol. Plant. 77: 457-464.

BUCKE, C. 1976. Phytochemistry 7: 693-700.

CORT, W.M., T.S. viCENTE, E.H. WAYSEK and E.D. WILLIAMS. 1983. J. Agric. Food Chem. 31: 13301333.

FINCKH, B.F. and K.J. KUNERT. 1985. J. Agric. Food Chem. 33: 574-577.

FOYER, C.H. and D.O. HALL. 1976. Planta 133: 21-25. and B. HALLIWELL. 1977. Phytochemistry 16: 1347-1350.

GRIFFITH, O.W. 1980. Anal. Biochem. 106: 207-212.

GRUMBACK, K.H. 1983. Z. Naturforsch. 38c: 996-1002.

JONES, E., and R.E. HUGHES. 1983. Phytochemistry 22: 2493-2499.

LEUNG, H.W., M.J. vONG and R.D. MAVIS. 1981. Biochem. Biophys. Acta. 664: 266-272.

LICHTENTHALER, H.K., U. PRESENZEL, R. DOUCE and J. JOYARD. 1981.. J. Biochim. Biophys. Acta 641: $99-105$.

MACKAY, C.E., T. SENARATNA, B.D. MCKERSIE and R.A. FLETCHER. 1987. Plant Cell Physiol. 28

(7): 1271-1278.

PACKER, J.E., T.F. SLATER and R.L. WILLSON. 1979. Nature (London) 278: 737-738.

RENNENBERG, H. 1982. Phytochemistry 21: 2771-2781. SENERATNA, T., B.D. MCKERSIE and R.H. STENSON. 1985. Plant Physiol. 78: 168-171. 